\section{EPISTEMOLOGIA EM QUESTÃO: A EDUCAÇÃO FÍSICA NA VISÃO DOS PÓS-GRADUANDOS DA FEF-UNICAMP}

\author{
EPISTEMOLOGY IN QUESTION: PHYSICAL EDUCATION ACCORDING TO FEF- \\ UNICAMP GRADUATE STUDENTS
}

\section{EPISTEMOLOGÍA EN CUESTIÓN: LA EDUCACIÓN FÍSICA EN LA VISIÓN DE LOS ESTUDIANTE DE POSGRADO DE LA FEF-UNICAMP}

\author{
Mariella Brighenti Bortoluzzi ${ }^{*}$, Arnaldo Leitão**, Flávia Martinelli Ferreira***, \\ Mariana Zuaneti Martins ${ }^{\star \star \star *}$, Elaine Prodócimo*
}

Palavras chave: Conhecimento. Formação de conceito. Educação Física. Programas de pósgraduação.
Keywords: Knowledge. Concept formation Physical Education. Graduate Programs.

Palabras clave: Conocimiento. Formación de conceptos. Educación Física. Programas de Posgrado.
Resumo: $O$ estudo analisou as concepções de Educação Física de mestrandos e doutorandos de um programa de pós-graduação. A pesquisa de cunho qualitativo e quantitativo foi desenvolvida por meio de questionário respondido por alunos do programa da Faculdade de Educação Física da Unicamp. Os dados foram organizados e analisados recorrendo ao programa Interface de $\mathrm{R}$ pourles Analyses Multidimensionnelles de Textes et de Questionnaires (Iramuteq), e a uma análise hermenêutica. Os resultados obtidos nos permitem perceber: o caráter multidisciplinar da Educação Física e concepções que refletem um direcionamento à intervenção social e/ou voltadas ao campo científico como uma racionalidade que fundamenta a prática social, havendo diferenças entre esses dois aspectos de acordo com a área de investigação do respondente. Tais posições demonstram as disputas que permeiam o campo da pós-graduação em Educação Física, como reflexo do debate epistemológico travado nas últimas décadas, reforçando dualismos e apontando possibilidades com vistas ao diálogo.

Abstract: This study looks into Physical Education views expressed by graduate students (Master and Ph.D. candidates). Qualitative and quantitative research was conducted through questionnaires applied to students enrolled in the FEF-Unicamp Graduate Program. Data were organized and analyzed by the program Interface de R pour les Analyses Multidimensionnelles de texts et de Questionnaires (Iramuteq) and Hermeneutics analysis. The results allow us to find some trends: Physical Education's multidisciplinary nature; views that illustrate an orientation toward social intervention and/or the scientific field as a rationality supporting social practice, showing differences between these two aspects according to students' research areas. These stances indicate disputes between graduate areas of Physical Education which reveals the epistemological debate going on in the last decades, reinforcing dichotomies and pointing out some solutions based on dialogue.

Resumen: Este estudio analiza las concepciones de Educación Física de estudiantes de posgrado (maestría y doctorado). La investigación se desarrolló a través de cuestionario respondido por alumnos matriculados en el Programa de Posgrado de la Facultad de Educación Física de la Unicamp. Los datos fueron organizados y analizados utilizando el programa Interface de $\mathrm{R}$ pour les Analyses Multidimensionnelles de textes et de Questionnaires (Iramuteq) y un análisis hermenéutico. Los resultados permiten percibir algunas tendencias: el carácter multidisciplinario de la Educación Física; concepciones que reflejan tendencias a la intervención social y/o centradas en el campo científico como una racionalidad que fundamenta la práctica social, habiendo diferencias entre esos dos puntos, de acuerdo con el área de investigación de quien contesta. Estas posiciones exponen las disputas que se dan en el posgrado como reflejo del debate epistemológico trabado en las últimas décadas, reforzando dualismos y señalando posibilidades con vistas al diálogo.
*Universidade Estadual de Campinas. Campinas, SP, Brasil. E-mail: maribortoluzzi@gmail.com; elaine@fef.unicamp.br

${ }^{* *}$ Instituto Federal do Sul de Minas. Pouso Alegre, MG, Brasil. E-mail: aleita013@gmail.com

*** Universidade de Brasília. Brasília DF, Brasil.

E-mail: laviamartinelli@uol.com.br

**** Universidade Federal do Espírito Santo.Vitória, ES, Brasil.

E-mail: faviamartinelli@uol.com.br

Recebido em: 07-08-2017 Aprovado em: 05-02-2018

$\mathrm{DOl}$ http://dx.doi.org/10.22456/1982-8918.75539 (c) (1) (3) Licence 


\section{INTRODUÇÃOO}

A Educação Física (EF), como prática social e área de conhecimento, é objeto constante de discussões e debates. Desde o século XIX, a conformação desse campo convive com duas matrizes distintas, protagonizadas, por um lado, pelas investigações e teses dos cursos superiores de medicina e, por outro lado, pelos manuais de ginástica, com preocupações pedagógicas propostas a partir de experiências concretas dos métodos europeus (HALLAL; MELO, 2017). Na visão dos autores, estas podem ser consideradas as primeiras iniciativas de práticas científicas no interior da EF, já marcadas por essa dualidade no modus operandi na forma de produção de conhecimento (FERREIRA NETO, 2005). A pós-graduação, nas últimas quatro décadas, tem sido o lócus de disputa que refrata e fomenta demandas no campo da $\mathrm{EF}$, de modo que compreender os sentidos revelados pelos seus agentes sobre esse debate epistemológico é fundamental para entender os atuais rumos da área.

A partir da década de 1970, os programas de pós-graduação em EF passaram por um processo de consolidação no cenário científico brasileiro (KOKUBUN, 2003). O primeiro curso de mestrado na área foi criado em 1977, na Universidade de São Paulo (USP), pioneira também, em 1988, com a criação do curso de doutorado, principalmente com as contribuições de docentes e pesquisadores oriundos de outros programas de pós-graduação do Brasil e do mundo. Naquele momento, os principais impulsos para a consolidação do campo científico, no âmbito da pós-graduação brasileira em EF advinham, predominantemente, da área biodinâmica, embora outras áreas também existissem (HALLAL; MELO, 2017). A partir da década de 1990, observamos a difusão de programas e a diversificação das áreas de concentração e linhas de pesquisa, aumento do número de laboratórios e projetos de pesquisa e a criação de periódicos específicos, que contribuíram com a divulgação da produção científica da área ${ }^{1}$ (MANOEL; CARVALHO, 2011). Foram consolidadas áreas de concentração distintas, orientadas tanto pelas Ciências Naturais quanto pelas Ciências Sociais e Humanas².

Esse processo de consolidação e expansão da pós-graduação da EF foi permeado por conflitos e tensões, como destacam Lovisolo (1998), Betti et al. (2004) e Manoel e Carvalho (2011). As disputas internas do campo e uma análise das áreas de concentração de pesquisa na pós-graduação possibilitam identificar um sobressalto da subárea da biodinâmica, que implica a concentração de recursos financeiros, do corpo docente e aumento de projetos de pesquisa (MANOEL; CARVALHO, 2011). Essa valorização da política de incentivo a essa subárea de pesquisa na pós-graduação acompanha um processo histórico de construção de discursos científicos e práticas sobre o corpo que, desde o advento da modernidade, consolida uma representação de EF voltada para a instrumentalização, racionalização e construção científica do corpo, reduzindo-o a um fenômeno biológico.

A biologização ${ }^{3}$ da área foi tratada por diversos autores, como Medina (1983), Castellani Filho (2011), Betti (1991), Bracht (1999), Lovisolo et al.(2015). Estes autores, a partir da década

1 Segundo dados da Coordenação de Aperfeiçoamento Pessoal de Nível Superior (CAPES) $(2000,2013)$, os programas de pós-graduação em EF passaram de 16 em 2001 para 53 em 2013.

2 Segundo Manoel e Carvalho (2011), são três as tradicionais áreas de concentração nos programas de pós-graduação em EF, a biodinâmica, orientada pelas Ciências Naturais; a sociocultural e a pedagógica, orientadas pelas Ciências Sociais e Humanas. Esta, todavia, não é a única forma de subdividir a área da EF. Daolio (1998), por exemplo, divide em duas subáreas: sociocultural e biodinâmica. Ainda que a subárea sociocultural guarde diferenças quanto à matriz disciplinar com relação à subárea pedagógica, ao tratarmos do modus operandi da produção de conhecimento, faz sentido pensarmos a divisão em apenas duas naturezas distintas, uma advinda das Ciências Naturais (biodinâmica) e outra das Ciências Humanas (sociocultural e pedagógica), conforme informam Hallal e Melo (2017).

3 Entendemos a biologização da EF como um processo de valorização dos aspectos fisiológicos e mecânicos do movimento humano. 
de 1980, realizaram análises e levantaram críticas sobre a questão, levando a um movimento de tentativa de desbiologização $0^{4}$, questionando algumas das bases epistemológicas que sustentavam a referida biologização e fortalecendo outras possibilidades do fazer científico. Os distintos modus operandi configuraram uma dualidade no interior da área, dividida em duas subáreas que se apresentavam fragmentadas disciplinarmente. Esta dualidade na constituição da $E F$, que ainda parece perdurar em alguns aspectos, pouco tem contribuído para que os avanços científicos da área, cada vez mais especializada, se aproximem da prática profissional seja nas escolas, academias, clubes, posto de saúde ou no campo esportivo (HALLAL; MELO, 2017).

Diante disso, orientamos este estudo a partir das seguintes questões: quais as concepções de EF dos pós-graduandos em EF da FEF-Unicamp ${ }^{5}$ ? As concepções dos alunos apresentam compatibilidade com as discussões epistemológicas empreendidas no campo acadêmico? As representações dos pós-graduandos estão relacionadas às diferentes áreas de concentração do programa a que estão vinculados?

Partimos da premissa de que nossas escolhas e valores são mediados pela história e cultura de nosso tempo. Assim, analisar as concepções dos pós-graduandos em EF envolve, conforme Gadamer (1999), apreender muito mais do que quem escreveu quis dizer. O autor esclarece que a expressão da individualidade é sempre uma manifestação total do viver, ou seja, qualquer reflexão pessoal traz no bojo aspectos da história em comum, do mundo compartilhado. Portanto, ressalta Merleau-Ponty (2009), as reflexões sobre nossas experiências podem fazer emergir alguns aspectos de nossas referências, mas é preciso colocar constantemente à prova e descobrir tudo aquilo que é aparentemente dado.

Dessa forma, o objetivo deste estudo foi analisar as concepções de EF dos alunos regularmente matriculados no programa de pós-graduação da FEF-Unicamp no ano de 2015. Com isso, buscamos identificar os nexos de vinculação entre o epistemológico e o histórico, dos discursos implícitos que atravessam o dito, como sugerido por Bracht (2003). Considerando esta importância, entendemos que o presente estudo pode contribuir, a partir das diferentes "formas-de-ser"6 da EF, para o debate sobre o estatuto epistemológico da área. Consideramos fundamental conhecer e considerar como e o que os agentes do campo refletem sobre a área dentro da qual produzem conhecimento, em uma tentativa de ampliar o horizonte das nossas compreensões, muitas vezes aprisionadas em tradicionais "castelos epistemológicos"7.

\section{DEBATE EPISTEMOLÓGICO DA EDUCAÇÃO FíSICA NA ATUALIDADE}

Os debates epistemológicos na EF, por vezes, foram penetrados por conceitos e finalidades apropriados de outras instituições e campos, sem muitas reflexões sobre seus postulados e seu objeto (BRACHT, 2003). A própria instituição escolar "pedagogizou" o discurso médico e militar, e, mais recentemente, discursos relacionados a esporte e saúde. Ou seja, o debate epistemológico hegemônico da área sofre constante concorrência de novas práticas e demandas sociais que, consequentemente, implicam uma revisão constante.

\footnotetext{
4 Conceito debatido em Lovisolo et al.(2015).

50 Programa de pós-graduação da FEF-UNICAMP foi criado em 1988, com o curso de mestrado para, posteriormente, em 1993, inaugurar seu curso de doutorado. Até 0 ano de 2015, a instituição formou 585 mestres e 261 doutores. Atualmente, o programa é composto por três áreas de concentração: Atividade Física Adaptada, Biodinâmica do Movimento e Esporte e Educação Física e Sociedade.

6 Expressão utilizada por Rezer, Nascimento, Fensterseifer (2011).

7 Idem anterior.
} 
Na década de 1990, os congressos do Colégio Brasileiro de Ciências do Esporte (CBCE) foram palco de intensos debates sobre a temática epistemológica da EF, e, em 2002, o próprio CBCE instituiu o Grupo de Trabalho Temático (GTT) Epistemologia como forma de manutenção e centralização das discussões. Outra importante contribuição veio das revistas de divulgação científica, que organizavam números especiais para discutir a identidade da EF${ }^{8}$.

Nesse contexto, Betti (1996) identificou dois grandes grupos de discussão teóricoepistemológica da EF brasileira: a matriz científica e a matriz pedagógica. A matriz científica é caracterizada pela busca de um estatuto científico próprio, que tem como principal expoente a obra de Tani et al. (1988). Já a matriz pedagógica reconhece a EF como uma área de intervenção social imediata, de prática pedagógica, que tematiza os conteúdos da cultura corporal ou cultura de movimento, referenciando em especial as contribuições de Bracht (1992, 1993). Essa classificação foi uma tradução da dualidade entre a subárea da biodinâmica e a subárea sociocultural/pedagógica, que, conforme apontamos, remontam às origens das então incipientes práticas científicas na EF no século XIX.

A polarização entre a matriz científica e a matriz pedagógica tem sido abandonada nas classificações epistemológicas da área (BETTI, 2005). Isso porque ambas as subáreas compreendem a ciência como uma forma de produção de conhecimentos que pode contribuir para fundamentar a prática social. Entretanto, na medida em que a fragmentação das subáreas não se retrai, a dificuldade de diálogo entre ambas se mantém e, por conseguinte, também se amplia a distância entre os saberes produzidos no campo científico e a intervenção profissional (HALLAL; MELO, 2017).

Por isso, é preciso ter em vista que essas classificações, das matrizes epistemológicas da EF, são importantes, mas podem gerar dualismos que, por vezes, impossibilitam enfrentar os desafios mais amplos da área. Betti (2005) acrescenta que esse debate não deve buscar uma unidade epistemológica, visto que a EF tem tradições disciplinares muito diferentes, com pressupostos filosóficos e político-ideológicos incompatíveis. Pelo contrário, o autor propõe que devemos valorizar a diversidade epistemológica, a convivência e o diálogo entre as subáreas, e a busca de fundamentos capazes de responder às demandas da sociedade. Assim, segundo Hallal e Melo (2017), a hegemonia de uma determinada concepção ou subárea de EF e 0 respectivo enfraquecimento das outras subáreas podem acarretar a fragilização acadêmica da área.

Uma análise teórico-epistemológica das produções científicas da EF revela que 0 atual momento histórico é extremamente complexo (REZER; NASCIMENTO; FENSTERSEIFER, 2011). A pluralidade de concepções expressa a disputa de diferentes intenções políticoepistemológicas no cenário da EF. Nesse sentido, o atual debate apresenta uma série de matrizes epistemológicas possíveis, bem como classificação e descrições delas, de modo que o empreendimento de interpretá-las está sempre sujeito a questionamento (ALMEIDA et al., 2012). No entanto, os agentes no campo científico posicionam-se politicamente perante a sociedade, o que implica seus projetos éticos de intervenção. Qualquer discurso científico está carregado de valores e intencionalidades que buscam legitimar determinadas práticas sociais. A reflexão sobre as concepções e referências pode contribuir para esclarecer os rumos atuais da EF. 


\section{PROCEDIMENTOS METODOLOGICOS}

Para atingir o objetivo de desvelar as concepções de EF que se encontram explícitas e implícitas no discurso dos alunos matriculados no programa de pós-graduação da FEF-Unicamp no ano de 2015, realizamos uma pesquisa de cunho quali-quantitativo. Utilizamos o programa Iramuteq para realizar a análise quantitativa dos dados, conjuntamente com uma análise de cunho qualitativo desenvolvida com base na perspectiva hermenêutico-dialética, com especial atenção para os direcionamentos a partir das obras de Habermas (1987), Gadamer (1999) e Stein (1987).

\subsection{Participantes e instrumento de produção de dados}

Inicialmente foi realizado um levantamento junto à secretaria de pós-graduação da FEF-Unicamp para quantificar os alunos regularmente matriculados no ano de 2015. Todos os pós-graduandos foram convidados a participar, dentre os quais 49 aceitaram compor o estudo 9 .

Do total de 49 respostas, 38 foram obtidas em uma reunião discente da pós-graduação, realizada no dia 25 de março de 2015, data em que o questionário foi apresentado aos alunos, juntamente com o Termo de Consentimento Livre e Esclarecido (TCLE) ${ }^{10}$. Posteriormente foram enviados o TCLE e o questionário, via correio eletrônico, aos demais pós-graduandos, sendo obtidas 11 respostas.

Dentre os participantes, 27 são estudantes de mestrado e 22 de doutorado. Entre as três áreas dos cursos de pós-graduação, os alunos estão assim divididos: 16 da área de Educação Física e Sociedade, 25 da área de Educação Física Adaptada e sete da área de Biodinâmica do Movimento e Esporte; um não informou sua área específica. Quanto ao gênero, os sujeitos dividem-se em 17 homens e 32 mulheres.

O questionário é constituído de uma primeira parte com 13 questões fechadas que contextualizam e traçam um perfil do participante, indagando quanto ao gênero, nível de pósgraduação, área de concentração e ano de ingresso, além de informações relativas à formação inicial, sobre a instituição de ensino superior frequentada e o ano de egresso. A segunda parte do questionário é composta de uma questão aberta: Qual a sua concepção de Educação Física?

\subsection{0 programa Iramuteq}

iramuteq é um programa estatístico usado para análises textuais, criado na França e traduzido para o português em 2013. Possibilita que se façam análises estatísticas sobre variáveis qualitativas, a partir de corpus textuais, desde as mais simples, como lexicografia básica e o cálculo da frequência de palavras, até análises multivariadas, como uma classificação hierárquica descendente e análises de similitude (CAMARGO; JUSTO, 2013).

A análise de similitude, também nomeada análise de semelhanças, permite "[...] colocar em evidência a organização dos dados, identificando uma estrutura entre eles" (PEREIRA,

9 Os sujeitos de pesquisa estavam regularmente matriculados no programa de pós-graduação em EF da FEF-Unicamp. De acordo com o Anuário Estatístico da Unicamp (2016), em 2015, eram 71 discentes no mestrado e 92 no doutorado, totalizando uma população de 163 pessoas. Excluem-se desta população quatro autores deste artigo que, à época, faziam parte do corpo discente. Fizeram parte da amostra $31 \%$ da população total.

10 O projeto foi aprovado no Comitê de Ética em Pesquisa da Unicamp sob número CAAE 38332814.3.0000.5404. 
1997, p.53). Analisa a relação de ocorrência entre as palavras, com indicações da conexidade entre elas. A partir das relações estabelecidas, foram construídas imagens destas conexões.

A análise iniciou-se com a inserção das 49 respostas obtidas durante a produção de dados no programa Iramuteq. Todas as respostas foram aglutinadas em um único corpus textual, submetido a uma análise lexicográfica clássica. Esta primeira triagem identificou e reformatou as unidades de texto, gerando a quantidade, frequência média e frequência de palavras hápax (palavras que aparecem apenas uma vez). Na sequência, o programa reduziu as palavras com base em suas raízes e, além disso, identificou as chamadas formas ativas e suplementares. Formas ativas são as palavras representativas, geralmente substantivos, adjetivos e verbos e formas suplementares são, geralmente, preposições e advérbios (CAMARGO; JUSTO, 2013). Posteriormente as palavras passaram pelo processo de lematização com a finalidade de encontrar suas variações. Os verbos foram reduzidos ao infinitivo, os nomes ao singular e os adjetivos ao masculino singular.

Em seguida, algumas palavras passaram pelo processo de fundição, de forma manual, ou seja, palavras com o mesmo significado, devido ao contexto em que aparecem, ou em formas de sinônimos, foram unidas em uma única palavra, considerada mais representativa, cujo número de frequência era mais alto, e, assim, seus números de frequência foram somados. Esta fundição é importante para reforçar alguns conceitos mais centrais, como, por exemplo: Indivíduo e Ser humano; Esportivo e Esporte; Atividade e Atividade Física.

\subsection{A perspectiva hermenêutico-dialética}

A hermenêutica auxilia na interpretação das respostas e compreensão dos sentidos explícitos e implícitos das falas obtidas, enquanto que o movimento dialético auxilia na contextualização das concepções no debate epistemológico da Educação Física atual e busca uma atitude crítica das ideologias, de confronto com o real. Com isso, o movimento hermenêutico-dialético possibilita compreender os sentidos e significados presentes nos discursos sociais que integram o contexto histórico.

Buscamos refletir acerca das condições objetivas de produção do conhecimento e suas repercussões em diferentes meios sociais, especialmente, por intermédio da visão dos pósgraduandos. Esse percurso metodológico permite reconhecer a nossa implicação dentro do campo acadêmico da EF.

\section{RESULTADOS E ANÁLISES}

Uma análise textual quantitativa das respostas permitiu identificar 2.352 palavras. Destas, 582 tiveram frequência maior que 1. Já as palavras com frequência igual a 1 (hápax) somaram 338. Dentre todas as palavras considerando-se apenas os verbos, substantivos e adjetivos, 486 foram classificadas como formas ativas, ou seja, palavras representativas, núcleos chaves para a compreensão do que foi dito ${ }^{11}$. Na Tabela 1estão as palavras de maior frequência nas respostas dos participantes. Optamos por expor as formas que apareceram com frequência de até 11 vezes:

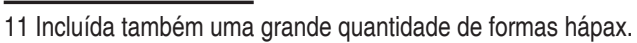


Tabela 1 - Palavras com maior frequência

\begin{tabular}{lc}
\hline FORMAS ATIVAS & FREQUÊNCIA \\
\hline Educação Física & 49 \\
Ser humano & 34 \\
Movimento & 33 \\
Área & 29 \\
Social & 25 \\
Estudo & 19 \\
Saúde & 19 \\
Área do conhecimento & 19 \\
Esporte & 17 \\
Cultura corporal & 15 \\
Corpo & 14 \\
Desenvolvimento & 13 \\
Diverso & 13 \\
Conhecimento & 12 \\
Educação & 11 \\
Lazer & 11 \\
\hline
\end{tabular}

Na sequência uma nuvem de palavras do corpus textual foi criada, agrupando as palavras ativas e organizando-as graficamente em função da sua frequência. Quanto mais alta a frequência de aparecimento, maior o tamanho da palavra na representação gráfica, assim como mais central é sua posição na nuvem (CAMARGO; JUSTO, 2013).

Figura 1 - Nuvem de palavras obtida a partir do corpus textual total

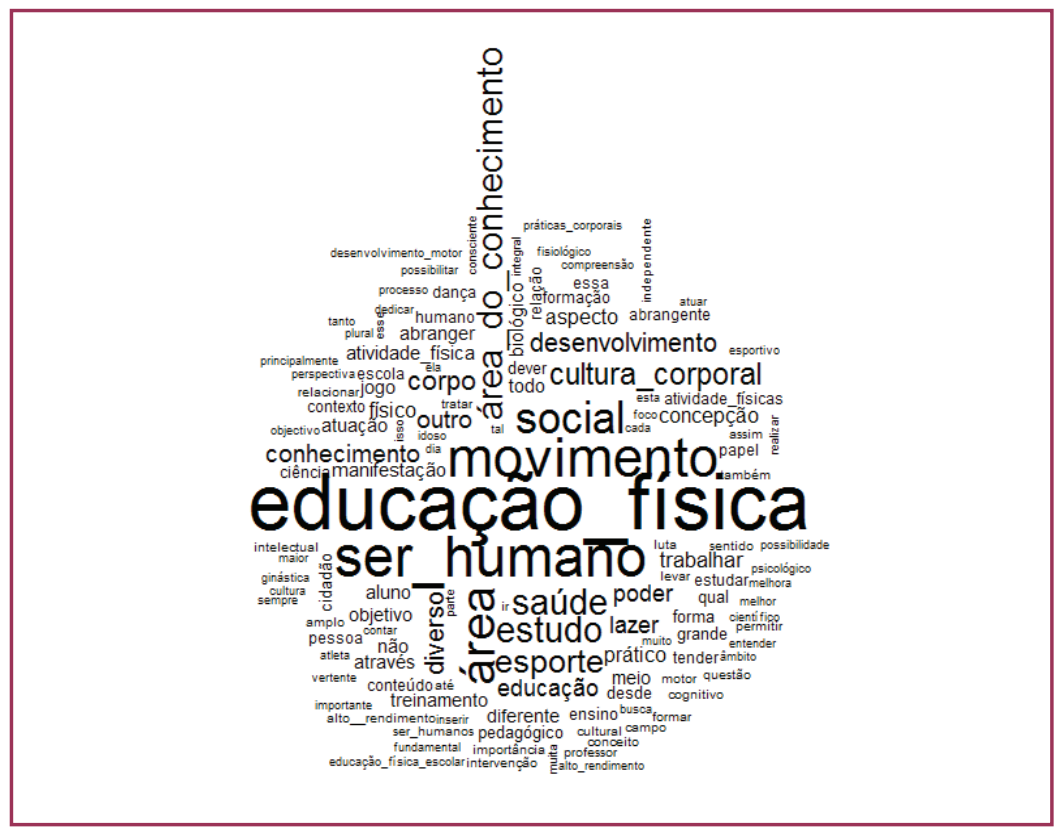

Fonte: Dados da pesquisa

Era esperado que a palavra Educação Física recebesse o maior número de citações, com uma frequência de 49 vezes. Considerando os 49 sujeitos investigados, poderíamos dizer que a palavra foi encontrada em $100 \%$ das respostas. No entanto, uma análise cuidadosa das 
respostas permite identificar que alguns sujeitos citaram mais de uma vez a palavra Educação Física, e outros nem mencionaram. A nuvem de palavras indica aEF como central, fazendo-a parecer muito relevante ao estudo, mas quando colocada no contexto das respostas, torna-se evidente que seu valor representacional é baixo, já que na maioria dos casos é empregada para introduzir a resposta à pergunta, com a frase: "A EFé...". Mesmo assim, é relevante mantê-la em sua posição central no gráfico de co-ocorrência para análise de similitude, para que possamos visualizar suas relações com as outras palavras que foram citadas.

Partindo do conceito central, o programa utilizado cria categorias e subcategorias. As subcategorias estão relacionadas ou contidas nas categorias de acordo com a relação contextual entre elas. As categorias estão assim definidas pelas palavras: ser humano, movimento, área, área do conhecimento, social, desenvolvimento e saúde, conforme demonstramos na Figura 2.

Figura 2 - Categorias e subcategorias das concepções de Educação Física

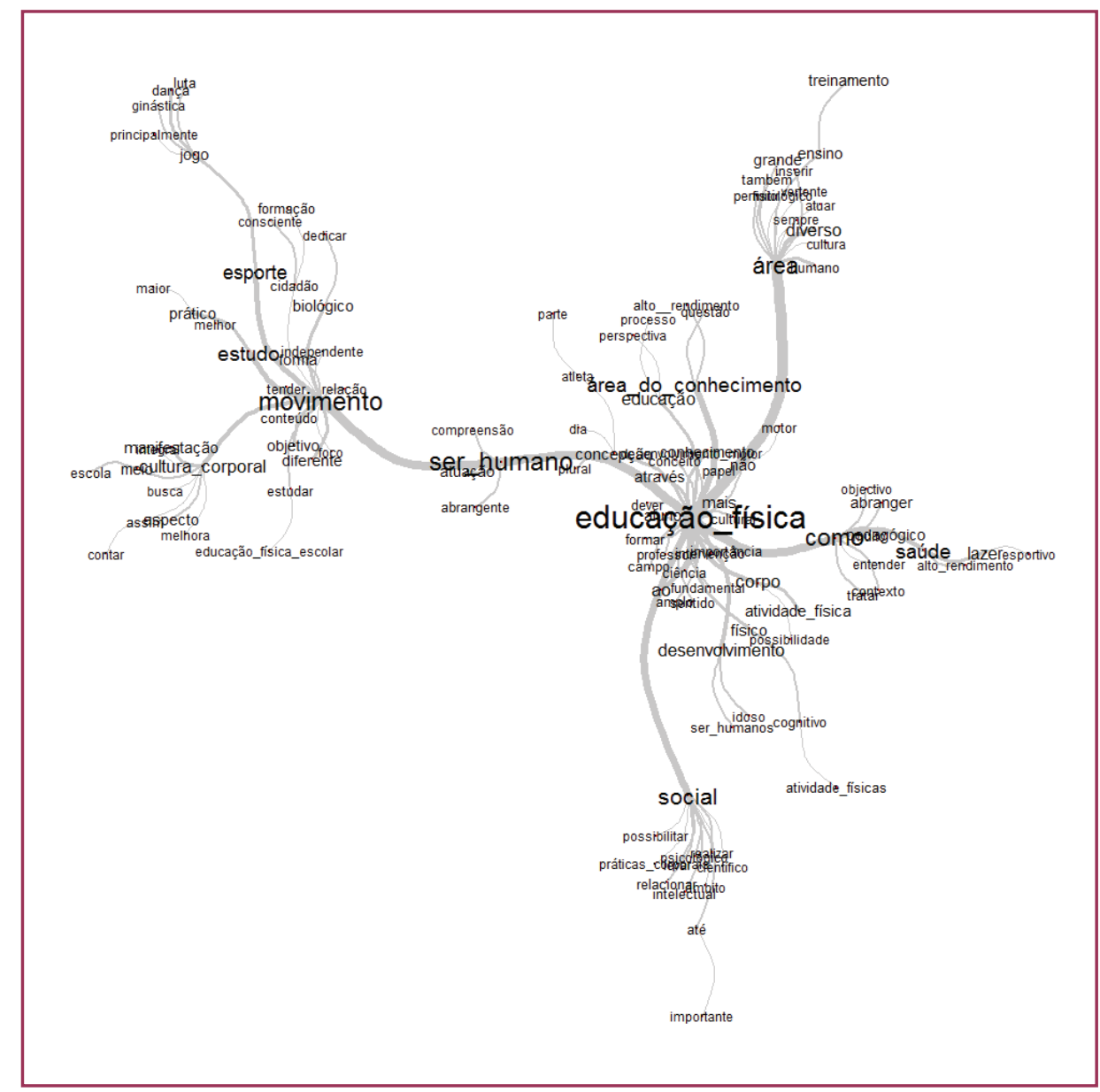

Fonte: Dados da pesquisa

Percebe-se pela figura que a categoria ser humano tem uma relação direta com a categoria movimento, unidas pelo mesmo eixo.Isso se deve à grande quantidade de respostas referindo-se à EF como a área responsável pelo estudo do ser humano em movimento. É notório também que as palavras estudo e esporte têm destaque como sendo subcategorias de movimento.

Da subcategoria esporte derivou a palavra jogo com vertentes para a ginástica, dança e lutas, o que pode ser um indício de que o entendimento da relação entre esporte e jogo esteja 
voltado para o contexto pedagógico, das funções educativas do jogo para o esporte. Ainda assim, não podemos eliminar a hipótese que este jogo esteja no contexto da formação de atletas, do esporte competitivo e do treinamento de alto rendimento. Porém, é possível inferir que o esporte e o jogo estão ligados às concepções mais pedagógicas da EF.

Na mesma linha, a presença de esporte e jogo, também relacionados à ginástica, à dança e às lutas, se direciona a uma concepção que compreende como objeto da EF as práticas corporais diversificadas, que são nomeadas por alguns dos pós-graduandos como cultura corporal de movimento. $O$ debate sobre a cultura corporal de movimento surge quando pesquisadores das subáreas pedagógica e sociocultural trazem para a EF a discussão sobre cultura dos estudos das Ciências Humanas e Sociais, especialmente da Antropologia, Sociologia, Psicologia Social, Semiótica, Fenomenologia. No âmbito da Educação Física Escolar (EFE), uma importante contribuição desta discussão vem de Soares et al. (2009, p.62), que definiram cultura corporal de movimento como um conjunto de "[...] temas ou formas de atividades, particularmente corporais, como as nomeadas anteriormente: jogo, esporte, ginástica, dança ou outras que constituirão seu conteúdo". Destacamos esta definição porque identificamos estas relações com a cultura corporal de movimento nas falas dos sujeitos, como nos trechos a seguir:

A Educação Física é uma área do conhecimento que desenvolve por meio de metodologias diversas as manifestações da cultura corporal como lutas, jogo, esporte, dança, ginástica, circo (S. 28).

[...]permita a vivência e experiência educativa a partir das diversas manifestações da cultura corporal, não se limitando aos esportes, mas apresentando todo o potencial desta cultura acumulada ao longo da história [...] (S. 19).

É importante ressaltar que a maioria dos pós-graduandos que responderam ao instrumento compõe as áreas de concentração na Atividade Física Adaptada e Educação Física e Sociedade do programa da FEF-Unicamp. Nota-se, então, a presença de palavras como Educação Física Escolar, escola, formação, cidadão, consciente, independente.Estas palavras podem estar relacionadas às metodologias de ensino da EFE mais difundidas e defendidas a partir da década de 1980 e que provavelmente fizeram parte da formação destes alunos. Igualmente, estas concepções nos informam sobre possíveis rupturas com concepções mais conservadoras de EF, uma vez que não se encontra a ocorrência de palavras inter-relacionadas como disciplina e competição.

As palavras alto rendimento, saúde, área de conhecimento e treinamento, de outro modo, aparecem com mais frequência na área de concentração da Biodinâmica do Movimento e Esporte. Como podemos observar na fala a seguir:" [...] o campo de trabalho remete-se à educação, saúde, lazer, treinamento, na perspectiva da iniciação, especialização e alto rendimento esportivo, seja no ensino, pesquisa, extensão [...]" (S. 34).

Outra categoria importante, com 29 aparições, assumindo um eixo próprio no gráfico da Figura 2 é a palavra área, que demonstra aproximação das falas dos pós-graduandos com as discussões epistemológicas empreendidas nos últimos anos. Como temos a seguir: " [...] é subdividida em três grandes áreas, humanas, biológicas e exatas [...]" (S. 49);“[...] área que converge conhecimento de diversas outras áreas, biológicas e humanas e tem como objetivo a educação através do movimento independentemente da área [...]" (S. 20).

A presença da noção de área nos permite vislumbrar duas interpretações nas respostas dos pós-graduandos. A primeira delas é que a EF assume o status de área de conhecimento 
científico na discussão epistemológica da década de 1990, conforme as análises de Bracht (2000) e Pardo e Rigo (2000). Outra interpretação, de acordo com Betti (2005), demonstra que a própria noção de área, muito embora esteja fundamentada na multidisciplinaridade, de conhecimentos advindos de outras disciplinas, representa um campo de intervenção profissional com objeto e finalidades próprias. Nesse sentido, percebe-se, na visão destes pós-graduandos, uma perspectiva de EF direcionada aos campos de intervenção. Neste caso, quando comparamos as duas interpretações sobre a área de conhecimento, notamos que, apesar da dualidade entre as naturezas distintas, elas têm em comum a afirmação do caráter científico da produção de conhecimento na EF. A diferença entre elas estaria nas ênfases, uma vez que na segunda fala o caráter pedagógico - "tem como objetivo a educação" - é mais salientado. De certa forma, tal concepção demonstra a sobrevida dos discursos epistemológicos que polarizam a matriz pedagógica e a científica (BETTI, 1996).

A categoria social também merece destaque, com frequência de 25 aparições, relacionada com frequência às palavras científico e intelectual, que apontam para forte influência de campos acadêmicos como o da Sociologia e da Psicologia. Mais evidente, no entanto, são os verbos que acompanham a categoria:possibilitar, realizar e relacionar,e o adjetivo importante de maneira destacada,que também possibilita interpretar a ligação da palavra social com as finalidades e responsabilidades da profissão na sociedade. Estas considerações indicam que os agentes da área estão incorporando o discurso ético-político da intervenção profissional, entendido como na fala seguinte:

A Educação Física exerce o papel fundamental no desenvolvimento de competências e habilidades importantes para os indivíduos, de crianças até idosos, sendo que essas habilidades não se restringem ao movimento, mas sociais, psicológicas, motoras e cognitivas [...](S. 24).

Em outra perspectiva está a categoria saúde, com 19 aparições, que também possibilita duas interpretações. Uma delas está relacionada ao pedagógico, das noções de saúde desenvolvidas no âmbito escolar, e também da saúde coletiva, e em outros campos de atuação como Sistema Único de Saúde (SUS), que indica uma discussão mais ampla de saúde. De acordo com Mezzaroba (2013), o profissional de EF, nestes espaços de cuidado com a saúde humana, parece estar mais associado ao sentido preventivo pedagógico. Outra vertente está relacionada comas palavras atividade física e alto rendimento,tanto no âmbito da intervenção quanto da pesquisa:

[...]pesquisa diferentes esferas bem caracterizadas do esporte de alto rendimento, do exercício físico e saúde e da Educação Física Escolar [...] (S. 6).

[...]fundamenta a prática de atividades físicas e esportivas em suas várias funções, lazer, alto rendimento, reabilitação, saúde, bem-estar social[...] (S. 35).

Chama atenção a pouca frequência da palavra lazer, com 11 aparições, e sua vinculação à categoria saúde. O programa de pós-graduação da FEF-Unicamp já foi referência nos estudos de lazer, com as pesquisas desenvolvidas por Nelson Carvalho Marcellino, de 1988 a 2001, dentre outros pesquisadores. Uma fala que ilustra esta concepção de Educação Física é destacada: [...] ela forma um cidadão mais crítico e consciente para as questões educacionais, esportivas e de lazer. Um cidadão que inclusive tendo esses conceitos ajude na melhora da cultura corporal de movimento [...](S. 46). 
Com isso, temos a possibilidade de diferenciar as análises por área de concentração. Com a finalidade de traçar um comparativo entre as três áreas, apresentamos as nuvens de palavras desvelando os conceitos centrais e mais representativos por área de concentração.

Figura 3 - Nuvens de palavras comparativas entre áreas

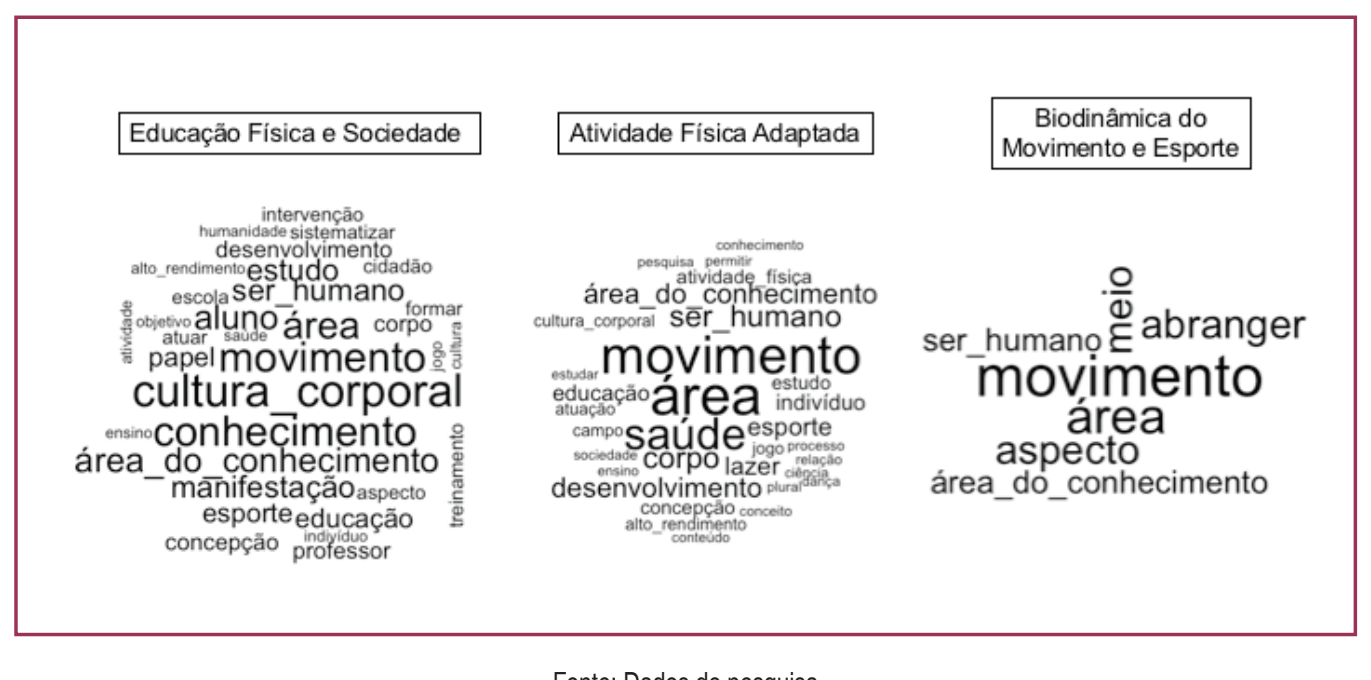

No grafo correspondente à área da Educação Física e Sociedade percebemos forte influência do debate pedagógico da cultura corporal de movimento,com as representações dos conceitos ligados às propostas pedagógicas atualmente vigentes, como: cidadão, desenvolvimento, formar, escola, professor, aluno, ser humano, intervenção, sistematizar. Percebe-se em tais concepções uma preocupação mais premente com a problemática da intervenção profissional. Contudo, o aparecimento centralizado das palavras conhecimento, área do conhecimento e estudodenota o avanço também do debate científico.

No grafo da área da Atividade Física Adaptada, percebemos a centralidade das palavras área e movimento,respaldadas pelo conceito de saúde, e demais representações que se relacionam com: corpo, desenvolvimento, lazer, esporte, ser humano, relação esta que demonstra como esta área transita entre o pedagógico e a saúde, mas que também se consolida nas discussões epistemológicas como área do conhecimento. As áreas de concentração da Educação Física e Sociedade e da Atividade Física Adaptada, por vezes, apresentam concepções de EF próximas, como é possível vislumbrar com a presença das palavras nos dois grafos correspondentes a cada área: cultura corporal, movimento, educação, ser humano.

Já o grafo respectivo à área de Biodinâmica do Movimento e Esporte denota forte influência da matriz científica, com destaque para a palavra movimento, que, relacionada às palavras área do conhecimento,possibilita confirmar que o estudo do movimento humano é uma característica histórica desta área. A ausência de qualquer menção à cultura, aos objetos da EF e às dimensões educacionais também chama atenção. No lugar de termos que se relacionam à cultura, notamos a presença da palavra "meio", que, ao mesmo tempo que demonstra que o ser humano não é compreendido de forma isolada no mundo em que vive, torna esse contexto "a-histórico", de forma semelhante à maneira pela qual este é tratado nos demais campos das Ciências Biológicas. Nesse sentido, demonstra que a subárea está distante das duas anteriores, mais alinhadas a um debate epistemológico próximo às Ciências Sociais e Humanas. 


\section{CONSIDERAÇÕES FINAIS}

As concepções dos pós-graduandos deEF reafirmam algumas das tendências do debate epistemológico da área. Em primeiro lugar, notamos uma compreensão da EF como uma área de conhecimento multidisciplinar que recebe influência de distintos campos científicos, sejam relacionados às Ciências Sociais e Humanas ou às Ciências Naturais. Evidentemente que, na medida em que os sujeitos participantes da pesquisa são pós-graduandos, não é de se estranhar que a dimensão científica da área ganhasse proeminência nas respostas.

Em segundo lugar, a divisão interna do campo entre subáreas se faz presente. As respostas dos pós-graduandos acompanharam os diferentes modus operandi das subáreas das quais fazem parte, demonstrando a fragmentação da EF. Apesar de todas as áreas centrarem-se sobre o objeto "movimento", o viés de engajamento com ele é distinto, uma vez que as respostas da área Educação Física e Sociedade o abordam a partir do referencial cultural, enquanto as da Educação Física Adaptada, pela problemática da saúde e as da Biodinâmica do Esporte, pelo referencial das Ciências Biológicas básicas. Portanto, nota-se ainda, no contexto estudado, a presença da fragmentação entre as subáreas.

Por fim, há a presença de algumas preocupações comuns com relação à educação e às questões culturais entre a Educação Física Adaptada e à Educação Física e Sociedade, que poderia denotar uma "zona de fronteira", de certa aproximação entre as áreas. Isso, entretanto, poderia ser fruto de um aspecto contextual do programa estudado, que apresenta as áreas de concentração organizadas dessa forma particular. Nossas análises não nos permitem fazer interpretações sobre esse aspecto, carecendo de outros dados que investigações futuras poderiam suprir.

\section{REFERÊNCIAS}

ALMEIDA, Ângela M. O.; CUNHA, Gleicimar G. Representações Sociais do Desenvolvimento Humano. Psicologia: Reflexão e Crítica, v.16, n.1, p.147-155, 2003.

ALMEIDA, Felipe Q.; BRACHT, Valter; VAZ, Alexandre. Classificações epistemológicas na Educação Física:redescrições...Movimento, v. 18, n.4, p. 241-263, 2012.

ANUÁRIO ESTATÍSTICO DA UNICAMP. Campinas:Assessoria de Economia e Planejamento, 2016.

BETTI, Mauro. Educação física e sociedade: a educação física na escola brasileira de $1^{\circ}$ e $2^{\circ}$ graus. São Paulo: Movimento, 1991.

BETTI, Mauro. Por uma teoria da prática. MotusCorporis, v.3, n.2, p. 73-127, 1996.

BETTI, Mauro. Educação física como prática científica e prática pedagógica: reflexões à luz da filosofia da ciência. Revista Brasileira de Educação Física e Esporte, v.19, n.3, p.183-197, jul./set. 2005. 
BETTI, Mauro et al. A avaliação da educação física em debate: implicações para a subárea pedagógica e cultural. RBPG Revista Brasileira de Pós-Graduação, v. 1, n.2, p. 183-194, 2004.

BRACHT, Valter.Educação Física e aprendizagem social. PortoAlegre: Magister, 1992.

BRACHT, Valter. Educação física/ciência do esporte: que ciência é essa? Revista Brasileira de Ciências do Esporte, v.14, n.3, p.111-118, 1993.

BRACHT, Valter. Educação Física \& Ciência: cenas de um casamento (in)feliz. ljuí: Ed. Unijuí, 1999.

BRACHT, Valter. Educação física \& ciência: cenas de um casamento (in)feliz. Revista Brasileira de Ciências do Esporte, v. 22, n. 1, p.53-63, set. 2000.

BRACHT, Valter. Identidade e Crise da Educação Física: um enfoque epistemológico.In: BRACHT, Valter et al. (org.). A Educação Física no Brasil e na Argentina: identidade, desafios e perspectivas.Campinas: Autores Associados, 2003. p. 13-29.

CAMARGO, Brigido V.; JUSTO, Ana M. IRAMUTEQ: um software gratuito para análise de dados textuais. Temas em Psicologia, v.21, n.2, p.513-518, 2013.

CASTELLANI FILHO, Lino. Educação Física no Brasil: a História que não se conta. 19. ed. Campinas, SP: Papirus, 2011.

DAOLIO, Jocimar. Educação Física brasileira: autores e atores da década de1980. Campinas: Papirus, 1998.

FERREIRA NETO, Amarílio. Leitura dos 20 e 25 anos do CBCE: política, comunicação e (in) definição do campo científico. In: FERREIRA NETO, Amarílio. (Org.). Leituras da natureza científica do CBCE. Campinas,SP: Autores Associados, 2005. p. 3-26.

GADAMER, Hans-Georg. Verdade e Método. Petrópolis: Vozes, 1999.

HABERMAS, Jürgen. Dialética e Hermenêutica. São Paulo: L\&PM, 1987.

HALLAL, Pedro C; MELO, Victor A. Crescendo e enfraquecendo: um olhar sobre os rumos da Educação Física no Brasil. Revista Brasileira de Ciências do Esporte, v.39, n.3, p.322-327, 2017.

KOKUBUN, Eduardo. Pós-graduação em Educação Física no Brasil: indicadores objetivos dos desafios e das perspectivas. Revista Brasileira de Ciências do Esporte, v. 24, n. 2, p. 9-26, 2003.

LOVISOLO, Hugo R. Pós-graduação e educação física: paradoxos, tensões e diálogos. Revista Brasileira de Ciências do Esporte, v. 20, n.1, p. 11-21, 1998.

LOVISOLO, Hugo R.; VENDRUSCOLO, Rosecler; GÓIS JUNIOR, Edivaldo. Recorte dos estudos socioculturais no campo da educação física. In: STIGGER, Marco P. (Org.). Educação Física + humanas. Campinas, SP: Autores Associados, 2015. v. 1, p. 181-202.

MANOEL, Edison. J.; CARVALHO, Yara M. Pós-graduação na educação física brasileira: a atração (fatal) para a biodinâmica. Educação e Pesquisa,v.37, n.2, p. 389-406, 2011.

MEDINA, João P. S. A Educação Física cuida do corpo... e "mente": bases para a renovação e transformação da educação física. Campinas, SP: Papirus, 1983. 
MERLEAU-PONTY, Maurice. O visível e o invisível. São Paulo: Perspectiva, 2009.

MEZZAROBA, Cristiano. Saúde na educação física: compreensões, reflexões e perspectivas a partir de um conceito amplo e social de saúde. In: DANTAS JUNIOR, Hamilcar S. et al.(Orgs.). Educação Física, esporte e sociedade: temas emergentes. São Cristóvão: Editora da UFS, 2013. v.5, p.25-42.

PARDO, Eliane; RIGO, Luis C. Educação Física como ciência: para sair do século XIX. Revista Brasileira de Ciências do Esporte, v. 22, n. 1, p.39-51, 2000.

PEREIRA, Costa. A análise de dados nas representações sociais. Análise Psicológica, v.1, n.15, p. 49-62, 1997.

REZER, Ricardo; NASCIMENTO, Juarez V.; FENSTERSEIFER, Paulo E. Um diálogo com diferentes "formas-de-ser" da Educação Física contemporânea - duas teses (não) conclusivas... Pensar a Prática, v. 14, n. 2, p. 1-14, maio/ago. 2011.

SOARES, Carmen Lúcia et al. Metodologia do ensino de Educação Física. São Paulo: Cortez, 2009.

STEIN, Ernildo. Dialética e Hermenêutica: uma controvérsia sobre método e filosofia. In: HABERMAS, Jürgen. Dialética e Hermenêutica. São Paulo: L\&PM, 1987. p.98-134.

TANI, Go et al. Educação física escolar: fundamentos de uma abordagem desenvolvimentista. São Paulo: EPU: EDUSP, 1988. 